\title{
BASES FILOSÓFICAS DE MEMÓRIAS PÓSTUMAS DE BRÁS CUBAS
}

\author{
Manoela Paiva Menezes*
}

\section{RESUMO:}

Pretende-se discutir em que termos Machado de Assis recorre à obra de Schopenhauer no romance Memórias Póstumas de Brás Cubas, publicado em 1881 como livro. Para isso, focamos no capítulo VII, "O Delírio", em que há referências contundentes a aspectos da filosofia de Schopenhauer, como os conceitos de Vontade, Corpo, Ideia e Fenômeno. Recorremos ao trabalho analítico de Roberto Schwarz em Um mestre na periferia do capitalismo, em que se expõe a noção de volubilidade como princípio formal, como ponto crucial do romance, que acarretará a identificação da fisionomia de classe do narrador Brás Cubas e seu papel no panorama histórico-social do Brasil de então. Nosso intuito é distinguir o uso irônico que Machado faz da obra de Schopenhauer, e argumentar em favor da hipótese de que se trata de um retrato crítico e real de um mecanismo social do Brasil contemporâneo a Machado. Em Memórias póstumas, o defunto-autor Brás Cubas narra retrospectivamente seu percurso, de acordo com as reflexões que lhe convêm: representa-se assim satiricamente o comportamento prepotente da classe dominante brasileira. Em consonância com o que afirma Schwarz, defendemos que há uma alternância sistemática de perspectivas expressas no comportamento de Brás Cubas. Portanto, a influência da obra de Schopenhauer é mais uma perspectiva dentre outras tantas, filosóficas, literárias etc. que são apresentadas, adotadas e descartadas ao longo do curso do romance.

Palavras-chave: Machado de Assis, Schopenhauer, teoria crítica.

\section{1) Brás e a derrota pessimista diante das forças do mundo, sob a influência de Schopenhauer.}

Neste primeiro momento, pretende-se analisar a possível influência dos conceitos de Vontade, Corpo, Ideia e Fenômeno expostos em $O$ mundo como vontade e como representação (publicado em 1818) e Metafísica do Belo (de 1820), ambos de Arthur Schopenhauer, sobre a concepção do capítulo VII, "O Delírio”, de Memórias Póstumas de Brás Cubas, de Machado de Assis (publicado em 1881 como livro).

Tendo ido à procura da obra completa de Machado de Assis, dividida em três volumes, pudemos encontrar menções explícitas a Schopenhauer.

*UNESP- Faculdade de Filosofia e Ciências, Campus de Marília. manoelamenezes@ hotmail.com. O trabalho faz parte da monografia para conclusão do bacharelado em filosofia, sob orientação da prof ${ }^{a} \mathrm{dr}^{\mathrm{a}}$ Ana Portich. 
Em Memórias póstumas de Brás Cubas, o defunto-autor, Brás Cubas, narra retrospectivamente seu percurso de acordo com as reflexões que lhe convêm, recurso este que possibilita a Machado de Assis a introdução de elementos que denunciam uma suspensão na narrativa. Há o momento em que o defunto-autor passa a relatar seu delírio, no final do VI capítulo, “Chimène, qui l'Eût Dit? Rodrigue, qui L'Eût Cru?”. Seu delírio relatado inteiramente no capítulo seguinte teve duração de vinte a trinta minutos, durante os quais é apresentado ao leitor o que se passava pela cabeça de Brás Cubas.

\section{Vontade e Corpo}

Primeiramente, Brás diz ter se sentido metamorfoseado em um barbeiro chinês, depois na obra Suma teológica, de São Tomás de Aquino. Quando restituído à forma humana, aparece um hipopótamo, que é o que leva Brás Cubas ao encontro com o conceito de Vontade personificado. O hipopótamo arrebata Brás Cubas levando-o à origem dos séculos através de uma corrida vertiginosa. O defunto-autor narra cuidadosamente o lugar em que se dá esta cena, descrevendo a paisagem. Neste ponto aparece um vulto, uma figura de mulher fitando-o, descrita do seguinte modo: "Tudo nessa figura tinha a vastidão das formas selváticas, e tudo escapava à compreensão do olhar humano, porque os contornos perdiam-se no ambiente, o que lhe parecia espesso era muita vez diáfano." (MACHADO DE ASSIS, 1959, p. 422). Esta figura de mulher, em relação à filosofia de Schopenhauer, será identificada nesta análise com o que há de mais profundo no nível da existência, a entidade irracional Vontade, que está para além do espaço, do tempo, sendo, portanto, metafísica. É a essência do sujeito e do mundo, tendo o corpo, que é fenômeno, apenas como via de acesso. Suspeitamos que, justamente pelo fato de a Vontade não ser uma representação nem estar no espaço e no tempo, é narrada enquanto delírio pelo defunto-autor.

Brás Cubas inicia um diálogo com essa figura, em que lhe pergunta quem é. A figura demonstra em sua resposta exercer poder sobre todas as coisas da natureza e isso assusta Brás. A figura o consola de maneira pessimista, pois diz que sua inimizade se afirma na vida através dos sofrimentos e insatisfações. Brás, consciente desse poder, pede à figura que lhe dê mais alguns anos de vida. Ela responde: "Para que queres mais alguns instantes de vida? Para devorar e seres devorado depois? Não estás farto do espetáculo e da luta?" (MACHADO DE ASSIS, 1959 p.423) 
Nesse trecho do delírio é expresso como a Vontade se manifesta sem que a alcancemos com a razão através das representações. Ela diz a Brás que lhe emprestou a vida e isso reforça o fato de que o corpo é a via de acesso para manifestação dessa entidade irracional conceituada como Vontade por Schopenhauer.

A maneira pessimista com que a figura respondeu quando Brás lhe pediu mais alguns anos de vida, evidencia um conflito salientado por Schopenhauer. Esse conflito diz respeito a uma luta que a Vontade trava consigo mesma, pois ela é uma carência que expressa, em todas as coisas e o tempo todo, a Vontade de ser suprida, mas nunca é satisfeita.

\section{Ideia e Fenômeno}

Ao ser levado pela figura de mulher ao alto de uma montanha, Brás Cubas descreve o que de lá pode ver:

(...) uma redução dos séculos, e um desfilar de todos eles, as raças todas, todas as paixões, o tumulto dos impérios, a guerra dos apetites e dos ódios, a destruição recíproca dos seres e das coisas. Tal era o espetáculo, acerbo e curioso espetáculo. A história do homem e da terra tinha assim uma intensidade que lhe não podiam dar nem a imaginação nem a ciência, porque a ciência é mais lenta e a imaginação mais vaga, enquanto o que eu ali via era a condensação viva de todos os tempos. Para descrevê-lo seria preciso fixar o relâmpago. (MACHADO DE ASSIS, 1959, p. 423)

A partir desta parte da narrativa, identificamos como a diferença entre Ideia e Fenômeno, expostas na filosofia de Schopenhauer, interfere na visão de Brás sobre curso do mundo.

Ele, ao ter a possibilidade de assistir ao desfilar dos séculos em seu delírio, nos expõe uma reflexão na qual é possível notar sua percepção de que a intensidade da história do homem e da Terra não é apreendida na forma de Fenômenos, que são maneiras limitadas de conhecimento.

Se Brás Cubas não delirasse e não conhecesse a essência Vontade personificada, o único modo de ele apreender a história do homem e da Terra seria na forma de Fenômenos.

Os Fenômenos, ou seja, como o mundo se apresenta ao conhecimento dos indivíduos, segundo Schopenhauer, são as expressões da Ideia. As Ideias não estão sujeitas ao devir, são eternas e permanentes, não estão no espaço e no tempo e residem fora do conhecimento dos indivíduos. 
Brás, em seu delírio, apreende a história do homem e da Terra na forma de Ideia, pois destaca que via uma condensação viva de todos os tempos, mas que a imaginação humana e a ciência não têm acesso ao que viu porque são regidas pelo princípio de razão suficiente e estão sujeitas ao devir. É através desse princípio de razão suficiente que os indivíduos concebem o tempo, espaço e causalidade, possibilitando a construção e organização das representações empíricas. Portanto, conseguem apreender apenas na forma de fenômenos.

O que Brás consegue ver em seu delírio são os diferentes graus de manifestação da Vontade expressos em sua forma original, Ideias. Quando diz que para descrever o que vê seria preciso fixar um relâmpago, entendemos que não compreende o curso do mundo na forma de Fenômeno, como, por exemplo, um relâmpago em movimento, mas sim na forma de Ideia, não perecível, mas fixa, do que é um relâmpago.

Brás, em seu delírio, teve o privilégio de ter contato com a essência Vontade, personificada em uma figura de mulher. Enquanto o resto dos indivíduos, através do princípio de razão suficiente, tem a possibilidade de conhecer apenas o mundo como representação, expresso por Fenômenos vindos (em diferentes graus) de uma Ideia essencial que visa (manifestando a Vontade) ser objeto do mundo empírico.

\section{2) Brás e a afirmação de seus privilégios através da fisionomia de classe}

Neste segundo momento, pretende-se analisar, através de outra perspectiva, o uso da filosofia de Schopenhauer em Memórias Póstumas de Brás Cubas, de Machado de Assis. Seria apenas uma influência schopenhaueriana por seu viés pessimista e metafísico, reduzindo-se ao que pontuamos no primeiro momento desse trabalho?

Ampliaremos a análise em consonância com o que afirma Roberto Schwarz em Um mestre na periferia do capitalismo. Schwarz nota, no plano formal do romance, um princípio que reflete um traço histórico-social brasileiro da classe dominante contemporânea a Machado de Assis.

Ao invés de entendermos o pessimismo schopenhaueriano como uma filosofia tratada a sério por Brás Cubas no capítulo (VII), “ O Delírio”, defenderemos que é somente mais uma filosofia exibida entre as tantas outras versadas. Notamos que faz parte apenas de uma das fisionomias apresentadas e descartadas por Brás Cubas, que cultiva um exercício constante de revezamento das poses. Schwarz, ao priorizar uma compreensão da lógica de todo o romance, destacou esse princípio formal: a volubilidade. 
Trocam-se estilos, escolas, técnicas, gêneros, recursos gráficos, tudo comandado pelo mesmo afã de uma superioridade "qualquer". Assim, a narrativa passa do trivial ao metafísico, ou vice versa, do estrito ao digressivo, da palavra ao sinal (o capítulo feito à moda shandyana, feito de pontinhos, exclamações e interrogações) da progressão cronológica à marcha à ré no tempo, do comercial ao bíblico, do épico ao intimista, do científico à charada, do neoclássico ao naturalista e ao chavão surrado, etc. etc. (SCHWARZ, pp.30-31)

Esse princípio formal é resultante de um desejo do narrador de demonstrar superioridade e amor-próprio, seja através do desrespeito às normas, da banalização de teorias e crenças, ou do desdém pela figura do leitor que procurará qual das fisionomias é a verdadeira. Utiliza todos esses artifícios para satisfação de seus caprichos que se impõem devido ao modo volúvel e debochado com que narra, exaltando aquilo que bem entende para logo em seguida o inferiorizar. O que se mantém não é o conceito de Vontade schopenhaeuriano, mas a vontade despótica do narrador que não permite - e nem lhe interessa - que enxerguemos aquilo em que acredita. Mas essa vontade despótica do narrador permite identificar uma conduta recorrente no personagem em todo o romance, o uso e o descarte daquilo que lhe convém.

A conduta identificada tem o referencial da classe dominante brasileira contemporânea ao romance. Em sua reflexão extraliterária, fundamental além dos aspectos formais, Schwarz afirma que essa alternância sistemática de perspectivas é produzida porque Machado atenta aos traços da sociedade brasileira.

Trata-se do mesmo movimento que a História permitia ou impunha à classe dominante brasileira tomada em bloco. Também esta devia visitar e absorver a cultura relevante do tempo, para patrioticamente aclimatá-la ao país, ou seja, associá-la ao instituto da escravidão, cujo núcleo de dominação pessoal discricionária contudo zombava da pretensão civilizada e já não era sustentável de público. Ora, a legitimidade apoiada em razões-de-ser antagônicas é um fator de inquietação, de deslocamento interior e exterior permanentes, de desidentificação de si. (SCHWARZ, p. 41.)

O cenário da época era de um Brasil recém-independente que, segundo Schwarz, continha uma ambivalência ideológica das elites brasileiras. O país era dividido entre o que os países europeus liberais e burgueses inspiravam e pressionavam e o sistema de exploração colonial vigente ainda vinculado fortemente ao tráfico negreiro, à escravatura, às relações paternalistas etc. O paternalismo, por exemplo, funcionava através das relações de favor que se estabeleciam entre, aqueles que não eram escravos, 
mas também não podiam trabalhar por não haver livre iniciativa, os agregados, e, os abastados, mediando a relação entre as classes. Portanto, a volubilidade se dava no comportamento prepotente da classe dominante que se afirmava burguesa moderna, mas dependia da preservação do regime escravista ou da manutenção dele.

Apesar de Brás Cubas impor sua vontade na narrativa alimentando afrontas, o princípio formal, a volubilidade, denuncia outro aspecto relevante para entender a crítica que Machado de Assis fez ao mecanismo social cindido entre filosofemas importados da Europa liberal e a fisionomia de classe de nossas elites. O capricho de Brás Cubas é realizado por ele mesmo de maneira deficiente. Há algo que não convence na exibição calculada de Brás. Segundo Schwarz, há uma superioridade e diminuição concomitante do que ele próprio diz. A superioridade é demonstrada pelo aspecto formal de falar o que lhe vem a cabeça, versando sobre variados assuntos ininterruptamente. A diminuição é demonstrada pelo enredo, por exemplo, nos casos em que expressa seus desarranjos mentais. No começo do capítulo "O Delírio", por exemplo, diz ter se sentido transformado na obra Suma teológica, mas logo em seguida diz ter se tornado um barbeiro chinês. Além disso, um hipopótamo o arrebata para o encontro com a figura de mulher que identificamos com um conceito da filosofia de Schopenhauer. Ele diminui a obra mencionada, pois é evidente seu interesse em apenas citá-la sem aprofundar e logo interromper o assunto para reafirmar que o poder narrativo é seu, trata-se, segundo Schwarz, de uma satisfação subjetiva através de uma frustração objetiva.

Schwarz diz quanto à volubilidade:

Ora ela funciona como substrato e verdade da conduta humana, contemporânea inclusive, que só não reconhecem os insanos, ora como exemplo de conduta ilusória, um tanto primitiva, julgada sobre o fundo de norma burguesa e utilizada como elemento de cor local e sátira. Esta incerteza de base, longe de ser um defeito, é um resultado artístico de primeira força, que dá a objetividade da forma a uma ambivalência ideológica inerente ao Brasil de seu tempo. (SCHWARZ, 2000, p. 46).

Com isso, podemos concluir que, o uso da filosofia de Schopenhauer em Memórias Póstumas se dá nesse registro volúvel, em que é exibida à moda da burguesia brasileira. Essa classe dominante representada por Brás Cubas no romance se define não a partir de uma filosofia ou uma conduta pertencente ao gênero humano, mas a partir de uma fisionomia de classe que se estabelece no interior de um mecanismo de relações sociais brasileiras contemporâneas a Machado de Assis. 
notemos que o desacerto entre as relações sociais do país e os quadros ideológicos do mundo burguês, transformados por isso mesmo em generalidades retóricas, não era invenção do escritor: cabia à vida cultural atestar vinculação europeia e moderna da elite, mais do que refletir as suas relações comas demais classes, donde a tendência do esforço intelectual para o clichê, com sua impotência cognitiva e eficácia gregária. (SCHWARZ, 2000, p. 174)

\section{REFERÊNCIAS:}

ASSIS, Joaquim Maria Machado de. Memórias póstumas de Brás Cubas. In: Coutinho, Afrânio (Org.). Machado de Assis: Obra completa, vol. I. Rio de Janeiro: Editora José Aguilar, 1959.

SCHARWZ, Roberto. Um mestre na periferia do capitalismo: Machado de Assis São Paulo: Duas Cidades, 2000.

SCHOPENHAUER, Arthur. Metafísica do belo. Tradução, apresentação e notas de Jair Barboza. São Paulo: Editora UNESP, 2003.

. O mundo como vontade e como representação. Tradução, notas de Jair Barboza. São Paulo: Editora UNESP, 2005. 